\title{
PULMONARY SHUNTING DURING ANAESTHESIA IN MAN
}

\author{
J. Gilbert Stone, Hoshang J. Khambatta, Robert T. Donham, and \\ Stuart F. Sullivan
}

THE LITERATURE is replete with measurements of pulmonary shunting (Q́s/Qt with the $\mathrm{F}_{\mathrm{I}_{2}}=1$ ) during anaesthesia. ${ }^{1}$ In our laboratory we have found a mean shunt of 3.4 per cent in 43 anaesthetized healthy beagle puppies. ${ }^{2-4}$ Others have reported similar minimal shunting under anaesthesia in the dog. ${ }^{5-8}$ However, in the dog there is evidence of collateral pulmonary ventilation ${ }^{9}$ which would enhance pulmonary gas exchange and might attenuate the development of a large shunt. In man, almost all studies during anaesthesia demonstrate a markedly increased Q̀s/Qt. In surgical patients Marshall, et al. ${ }^{10}$ showed a 4.4 per cent shunt prior to anaesthesia and a 12.8 per cent shunt after induction suggesting that in man the anaesthetic state per se was responsible for abnormal shunting. However, more recently, Marshall, et al. ${ }^{11}$ examined six healthy volunteers in their early twenties and reported that during anaesthesia the shunt fraction was less than 4 per cent. We have studied anaesthetized patients during anaesthesia and operation to determine whether in fact atelectasis with its consequent increase in shunting does occur in all who undergo general anaesthesia.

\section{METHODS}

$\dot{\mathrm{Q}}_{s} / \dot{Q}_{\mathrm{t}}$ was measured in 22 patients undergoing mostly major neurosurgical operations. Age varied between 23 and 61 years. All possessed good physique and were active until admission; however, thereafter some were sedated and on bed rest for days preoperatively. Some smoked cigarettes, but none gave a history or had physical findings indicative of pulmonary disease. Routine chest X-rays were all reported as normal. Extensive preoperative testing of pulmonary function was not attempted.

Halothane (0.5-2.0 per cent) and oxygen were the sole inhalational agents used for anaesthesia, and ventilation was controlled without positive end-expiratory pressure or resistance. The depth of anaesthesia, the degree of muscle relaxation and the $\mathrm{PaCO}_{2}$ differed among patients, as premedication, induction and the course of anaesthesia were managed by anaesthetists apart from the study. Indwelling radial artery and right ventricular monitoring lines were inserted following induction and so preanaesthetic control measurement could not be obtained. Two shunt determinations were made during the course of operation, separated by as large

From the Department of Anesthesiology, Columbia Presbyterian Medical Center, New York, New York 10032.

Supported in part by NIGMS Grant 09069.

The authors wish to express their appreciation to Emaduddin Khan for his excellent technical assistance and to S.H. Ngai for his advice in preparation of this manuscript.

Canad. Anaesth. Soc. J., vol. 22, no. 6, November 1975 
an interval as was feasible. An attempt was made to sample only during periods when stable anaesthetic conditions had prevailed for at least 30 minutes, and similar anaesthetic techniques were employed. Blood pressure, heart rate, body temperature and in 12 patients dye-dilution cardiac output measurements were recorded at the time of blood gas sampling.

Arterial and mixed venous blood samples were drawn anaerobically into iced heparinized sterile glass syringes and analyzed expeditiously for $\mathrm{P}_{\mathrm{O}_{2}}, \mathrm{P}_{\mathrm{CO}_{2}}$ and $\mathrm{pH}$ on an IL 313 analyzer. When a delay of more than ten minutes occurred between sampling and blood-gas analysis, a correction factor was employed to compensate for oxygen decay in the blood. ${ }^{4} \mathrm{~A}$ second adjustment was made upon the $\mathrm{Pa}_{\mathrm{O}_{2}}$ to compensate for the oxygen electrode-blood gas $\mathrm{P}_{\mathrm{O}_{2}}$ difference. ${ }^{4} \mathrm{One} \mathrm{pH}$ and one $\mathrm{CO}_{2}$ electrode sufficed for both arterial and venous blood, but two oxygen electrodes were used so that the high oxygen calibrating gas closely corresponded to the $\mathrm{P}_{\mathrm{O}_{2}}$ of each sample. All determinations were done in duplicate. The temperature of the water bath was $37^{\circ} \mathrm{C}$, but patient body temperature usually was not and so all blood gases were corrected for temperature. ${ }^{12}$ The shunt fraction was calculated using the following formula:

$$
\grave{Q}_{s} / \grave{Q}=\left(\mathrm{Cc}_{\mathrm{O}_{2}}-\mathrm{Ca}_{\mathrm{O}_{2}}\right) /\left(\mathrm{Cc}_{\mathrm{O}_{2}}-\mathrm{C}_{\mathrm{O}_{2}}\right)
$$

where $\mathrm{C}_{\mathrm{O}_{2}}=(1.39 \times \mathrm{Hb} \times$ per cent saturation $)+\left(\alpha \times \mathrm{P}_{\mathrm{O}_{2}}\right)$, and $\dot{\mathrm{c}}$, a, and $\overline{\mathrm{v}}$ represent end pulmonary capillary, arterial and mixed venous values, respectively. Oxygen content was therefore calculated and oxygen saturation derived from measured blood gases using the data of Severinghaus ${ }^{12}$ and Roughton and Severinghaus. ${ }^{13}$ Oxygen solubility in blood $(\alpha)$ was corrected for temperature and haemoglobin, ${ }^{14}$ but $P_{\pi 0}$ was not measured.

The Students t-test was used to determine statistical significance.

\section{Results}

Data from individual patients are presented in Table I. They indicate the number of hours following induction when each determination of $\dot{Q}$ / $Q \mathbf{t}$ was made as well as the cardiovascular and pulmonary parameters measured simultaneously. For most patients the interval between was substantial, and the clinical conditions similar.

Pontoppidan, et al. stated that "In normal man at rest, Q̀s/Q்t varies from 2 to 5 per cent of the cardiac output."15 Our anaesthetized patients fell into two distinct groups; those whose shunt fractions were roughly in the normal range, and those that were markedly abnormal. The first 15 patients listed in Table I exhibited minimal pulmonary shunting with a mean of $3.9 \pm 0.3$ per cent (S.E.M.). The average age of these 15 patients was 37 years, ten years younger than those who had increased shunting and significantly younger as determined by variance analysis $(\mathrm{F}=4.6, \mathrm{P}<0.02)$. Age correlated fairly well with $\dot{\mathrm{Q}} \mathrm{s} / \mathrm{Q} t$; the correlation coefficient was $0.57(\mathrm{P}<0.01)$.

Shunt was unaltered by the passage of time under anaesthesia. Mean $\dot{Q} / \mathrm{Q} t$ in the early period was $7.0 \pm 1.1$ per cent and in the later period, $6.9 \pm 1.2$ per cent (an insignificant difference). When examined separately, those with minimal 


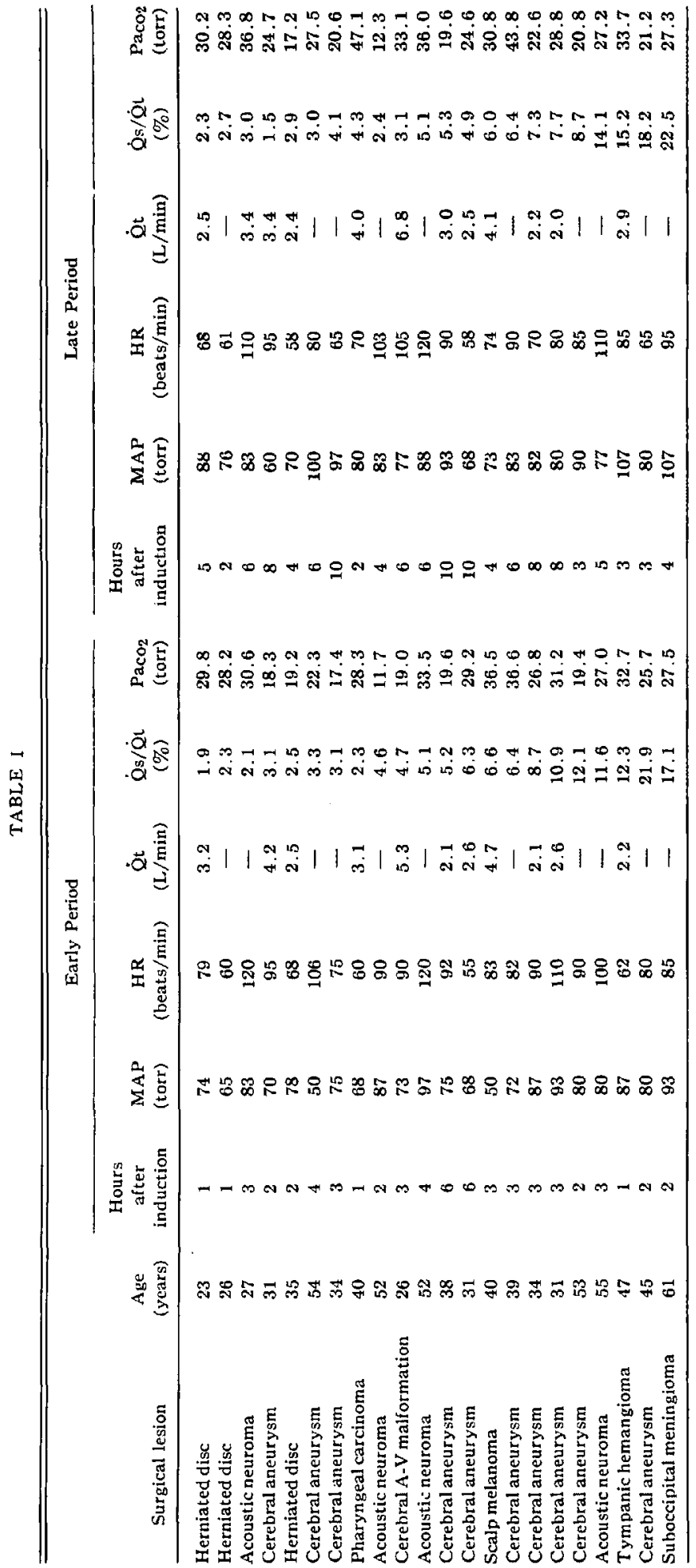


shunting had a mean $Q s / Q$ t of $4.0 \pm 0.4$ per cent in the early period and $3.8 \pm 0.4$ per cent in the later one (insignificant statistically), and those with increased shunts had a mean $Q$ s $/ Q$ t of $13.5 \pm 1.7$ per cent in the early period and $13.4 \pm 2.2$ per cent in the later one (also statistically insignificant).

Many of the neurosurgical patients required hyperventilation to provide satisfactory operating conditions and so respiratory alkalosis was frequent, but the $\mathrm{PaCO}_{2}$ did not correlate well with $\dot{\mathrm{Q}}_{\mathrm{s}} / \mathrm{Q}_{\mathrm{t}}(\mathrm{r}=0.05)$ indicating that the level of ventilation did not affect the shunt.

The small size of the sample precluded an evaluation of the effect of smoking habits or preoperative sedation and bed rest upon the shunt.

\section{Discussion}

Pulmonary disease states and the aging process both cause airway closure early during expiration and long before the resting lung volume is reached. ${ }^{15}$ Trapped distal airspace gas rapidly reaches equilibrium with the mixed venous blood, and if reexpansion of the alveoli which now requires a greater opening force does not occur, atelectasis ensues and pulmonary oxygen exchange is disturbed. When elderly or sick patients are anaesthetized their preexisting abnormal shunts usually increase because the functional residual capacity (FRC) decreases with anaesthesia and an even greater discrepancy between the resting lung volume and the closing volume (CV) develops. ${ }^{16}$ The data from our older patients merely confirm this fact. However, young and healthy patients with minimal preoperative $\dot{Q}_{s} / \dot{Q}_{t}$ have not been studied during anaesthesia until recently, and new evidence indicates that anaesthesia does not decrease FRC in these individuals. ${ }^{17}$ Nor does the volume of trapped gas in the lungs increase. ${ }^{18}$ In other words, throughout the respiratory cycle the FRC remains well above the $\mathrm{CV}$ during anaesthesia in the young and healthy, and so atelectasis and increased shunting ought not to occur. Clearly data from the first 15 patients in Table I demonstrate minimal pulmonary shunting during anaesthesia and operation. Marshall, et al. recently reported six more anaesthetized subjects in whom $Q s / Q t$ was found to be within the normal range. ${ }^{11}$ Other papers which provide data from individual patients document that at least in some patients anaesthesia and operation were conducted without the development of pulmonary shunting. ${ }^{1,10-22}$ Certainly there is now adequate evidence in the literature so that one cannot dismiss normal values of Q $s / Q t$ during anaesthesia as merely erroneous measurement. More such reports would doubtless exist, if only $\dot{Q}$ / $Q \mathbf{t}$ did not require invasive measurements.

One situation where invasive monitoring is standard practice in the anaesthetized youngster is open heart surgery, but most of these patients have pre-existing pulmonary pathology. The pulmonary artery pressures can be normal preoperatively, however, if cardiac failure and pulmonary overcirculation are absent. Table II contains data during anaesthesia and opertion in five such patients. $\dot{Q}_{\mathrm{S}} / \hat{Q}_{\mathrm{t}}$ was measured after successful weaning from cardiopulmonary bypass just prior to closure of the median sternotomy. Blood pressures had returned to pre-bypass levels but cardiac output was not measured. The pleura were intact and the lungs were not compressed. Again the level of pulmonary shunting was minimal. 
TABLE II

\begin{tabular}{lcccc}
\hline \multicolumn{1}{c}{ Surgical lesion } & $\begin{array}{c}\text { Age } \\
\text { (years) }\end{array}$ & $\begin{array}{c}\text { Minutes } \\
\text { after bypass }\end{array}$ & $\begin{array}{c}\mathrm{Paco}_{2} \\
\text { (torr) }\end{array}$ & $\begin{array}{c}\mathrm{Qs}_{\mathrm{s}} / \mathrm{Q}_{\mathrm{t}} \\
(\%)\end{array}$ \\
\hline Pulmonary stenosis & 1 & 15 & 35.6 & 4.6 \\
Tetralogy of Fallot & 2 & 45 & 23.4 & 1.5 \\
Atrial septal defect & 15 & 60 & 59.9 & 5.0 \\
Atrial septal defect & 19 & 30 & 21.2 & 6.4 \\
Aortic stenosis & 22 & 25 & 32.0 & 5.9 \\
\hline
\end{tabular}

In the clinical environment in which these studies were done, it was not possible to determine $\dot{Q}$ / $\dot{t} t$ pre-operatively; hence we do not know whether the shunt fraction increased, decreased or remained unchanged with the institution of anaesthesia. Nevertheless, as no one has suggested that anaesthesia decreases pulmonary shunting, normal levels during anaesthesia are very significant.

However, we do not mean to infer that most surgical patients do not develop increased pulmonary shunting during anaesthesia. This is indisputable and reasonable, for many patients are elderly or obese or have pre-existing cardiopulmonary dysfunction; moreover, the lungs are often compressed at operation. Objection is raised only when this observation is expanded and inferences are drawn about all anaesthetized patients. We therefore conclude that in the young and healthy individual abnormal pulmonary shunting should not be considered an unavoidable consequence or sequela of anaesthesia.

\section{SUMMARY}

$\dot{Q} s / \dot{Q}$ t was determined during halothane and oxygen anaesthesia in 22 patients. All were believed to have no pulmonary dysfunction. A surgical operation was in progress and respiration was controlled. Q s/Qt was minimal in 15 of these patients (mean $3.9 \pm 0.3$ per cent), indicating that anaesthesia and operation can be conducted in man without a significant increase of pulmonary shunting. The level of shunting was increased in the other seven patients. In neither group was $\dot{Q} s / \dot{t}$ altered by the passage of time. Age varied between 23 and 61 years and was directly and significantly correlated to $\dot{\mathrm{Q}} \mathrm{s} / \dot{\mathrm{Q}} \mathrm{t}(\mathrm{r}=0.57, \mathrm{P}<0.01)$.

\section{RÉSUMÉ}

Chez 22 malades, les auteurs ont déterminé le QQs/Q்t au cours de l'anesthésie à l'halothane et à l'oxygène. Aucun de ces malades ne démontrait de dysfonction pulmonaire. Ces déterminations ont été faites au cours de la chirurgie et pendant que la ventilation était contrôlée. Chez 15 de ces malades, le Q́s/Q́t était minime ( $3.9 \pm 0.3$ pour cent); ces résultats indiquent que chez l'homme l'anesthésie et la chirurgie ne produisent pas nécessairement une augmentation significative du shunt pulmonaire. Toutefois, le pourcentage de shunt était plus élevé chez les sept autres patients. Dans aucun des deux groupes le Q̀s/Qt n'a été modifié par le temps. L'âge des malades variait entre 23 et 61 ans, et une correlation directe et significative fut notée entre lâge et le shunt $(\mathrm{r}=0.57, \mathrm{P}<0.01)$. 


\section{REFERENCES}

1. Marshall, B.E. \& WYChE, M.Q. Hypoxemia during and after anesthesia. Anesthesiology 37: 178-209 (1972).

2. Stone, J.G. \& Sullivan, S.F. Failure of shallow ventilation to produce pulmonary shunting in the anesthetized dog. Anesthesiology 32: 338-342 (1970).

3. Stone, J.G. \& Sullivan, S.F. Halothane anesthesia and pulmonary shunting. Anesthesiology 37: 582-587 (1972).

4. Stone, J.G. \& Sullivan, S.F. Pulmonary shunting during alveolar hypoventilation in the dog. Anesthesiology, 42: 443-450 (1975).

5. SchuUrmans-Stekhoven, J.H. \& Kreuzer, F. Shunt components of alveolar-arterial oxygen pressure difference and atelectasis. Resp. Physiol. 3: 192-202 (1967).

6. Funuma, S., Wildeboeh-Venema, F.N., Horie, S., Yokota, H., Honda, Y., SchuurmansStekhoven, J.H., \& Kreuzer, F. Pulmonary diffusing capacity in the dog as influenced by anesthesia and ventilatory regime. Resp. Physiol. 8: 311-331 (1970).

7. Yamamura, H., Kaito, K., Ikeda, K., Nakajma, M., \& Okada, K. The relationship between physiologic shunt and cardiac output in dogs under general anesthesia. Anesthesiology 30: 406-413 (1969).

8. LoH, L., SEED, R.F., \& SYkes, M.K. The cardiorespiratory effects of halothane, trichloroethylene and nitrous oxide in the dog. Brit. J. Anaesth. 45: 125-130 (1973).

9. MACKLEM, P.T. Airway obstruction and collateral ventilation. Physiol, Rev. 51: 368-436 (1971).

10. Marshall, B.E., Cohen, P.J., Klingenmaien, C.H., \& Aukbeng, S. Pulmonary venous admixture before, during, and after halothane: oxygen anesthesia in man. J. Appl. Physiol. 27: 653-657 (1969).

11. Marshali, B.E., Hoffman, D.A., Neufeld, G.R., \& Colton, E.T. Influence of induction agent on pulmonary venous admixture during halothane:oxygen anesthesia with controlled respiration in man. Canad. Anaesth. Soc. J. 21: 461-466 (1974).

12. Severinghaus, J.W. Blood gas calculator. J. Appl. Physiol. 21: 1108-1116 (1966).

13. Roughton, F.J.W. \& Severinchaus, J.W. Accurate determination of $\mathrm{O}_{2}$ dissociation curve of human blood above $98.7 \%$ saturation with data on $O_{g}$ solubility in unmodified human blood from $0^{\circ}$ to $37^{\circ}$. J. Appl. Physiol. 35: 861-869 (1973).

14. Christoforides, C. \& Henley-Whyte, J. Effect of temperature and hemoglobin concentration on solubility of $\mathrm{O}_{2}$ in blood. J. Appl. Physiol. 27: 592-596 (1969).

15. Pontoppidan, H., Ceffin, B., \& Lowenstein, E. Acute respiratory failure in the adult. Boston: Little, Brown and Co. (1973).

16. Pietak, S., Weenig, C.S., Hickey, R.F., \& Fairlex, H.B. Anesthetic effects on ventilation in patients with chronic obstructive pulmonary disease. Anesthesiology 42: 160-166 (1975).

17. Weenig, C.S., Pietak, S., Hrckey, R.F., \& Famley, H.B. Relationship of preoperative closing volume to functional residual capacity and alveolar-arterial oxygen difference during anesthesia and controlled ventilation. Anesthesiology 41:3-7 (1974).

18. Dow, H.F., WAhra, W.M., \& Craig, D.B. Airway closure, gas trapping, and the functional residual capacity during anesthesia. Anesthesiology 36: 533-539 (1972).

19. Marshall, B.E., Cohen, P.J., Klingenmaier, C.H., Neigh, J.L., \& Pender, J.W. Some pulmonary and cardiovascular effects of enfurane anesthesia with varying $\mathrm{PaCO}_{2}$ in man. Brit. J. Anaesth. 43: 996-1002 (1971).

20. Wyche, M.Q., Teichner, R.L., Kallos, T., Marshall, B.E., \& SMith, T.C. Effects of continuous positive-pressure breathing on functional residual capacity and arterial oxygenation during intra-abdominal operations. Anesthesiology 38: 68-74 (1973).

21. Nuni, J.F., Bercman, N.A., \& Coleman, A.J. Factors influencing the arterial oxvgen tension during anesthesia with artificial ventilation. Brit. J. Anaesth. 37: 898-914 (1965).

22. Bergman, N.A. Components of the alveolar-arterial oxygen tension difference in anesthetized man. Anesthesiology 28: 517-527 (1967). 